\title{
Ecological, recreational and educational potential of a small artificial wetland in an urban environment
}

\section{PN Gitau, GG Ndiritu \& NN Gichuki}

To cite this article: PN Gitau, GG Ndiritu \& NN Gichuki (2019) Ecological, recreational and educational potential of a small artificial wetland in an urban environment, African Journal of Aquatic Science, 44:4, 329-338, DOI: 10.2989/16085914.2019.1663721

To link to this article: https://doi.org/10.2989/16085914.2019.1663721

曲 Published online: 15 Nov 2019.

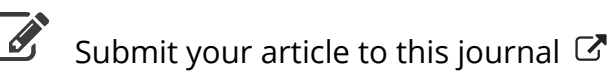

III Article views: 61

Q View related articles $\sqsubset$

View Crossmark data $₫$ 


\title{
Ecological, recreational and educational potential of a small artificial wetland in an urban environment
}

\author{
PN Gitau*, GG Ndiritu² (iD) and NN Gichuki ${ }^{1}$ \\ 1 School of Biological Sciences, University of Nairobi, Nairobi, Kenya \\ 2 School of Natural Resources and Environmental Studies, Karatina University, Karatina, Kenya \\ *Corresponding author, email: ngashpeter@gmail.com
}

\begin{abstract}
Pertinent questions remain on whether small, artificial wetlands, such as abandoned quarries play any ecological or socio-economic role in the environment. To increase information on roles played by small-sized artificial wetlands in the environment, an assessment study was carried out in the Lily Wetland, an abandoned flooded quarry in Karura forest in Nairobi City, Kenya. This study was guided by the idea that artificial wetlands can develop over time to acquire ecological characteristics similar to those of natural wetlands. Ecological information was collected on water physico-chemical characteristics, vegetation, birds and macroinvertebrates, whereas questionnaires were administered to assess recreational and educational values of the Lily Wetland. Inspection of Google Earth maps showed that the pond has not dried in the past fifteen years, with its area remaining relatively constant between dry $(0.29 \pm 0.03 \mathrm{ha})$ and wet $(0.36 \pm 0.06 \mathrm{ha})$ seasons. Water quality of the wetland was good: $\mathrm{pH}$ of 7.5-7.8; dissolved oxygen $=8.73 \pm 0.43 \mathrm{mg} \mathrm{l}^{-1}$; and clarity (Secchi disk reading) $=24.00 \pm 0.43 \mathrm{~cm}$. The biological component included 12 wetland plant species, 11 aquatic macroinvertebrate taxa, four species of wetland birds, and viable populations of fish and frogs. An assessment of the recreational and educational importance of the Lily Wetland, based on 34 respondents showed that 24 of the respondents visited Karura forest for recreational purposes, whereas 10 were there for educational purposes. Further analyses between the different benefits showed that the value of the forest, walking trails and wetland were significantly ranked important, when compared with the value placed on playing in fields and visiting the restaurants. Specifically, the Lily Wetland was regarded as important, because of its scenery, nature and recreational attributes. This study concluded that the Lily Wetland and other small wetlands in the urban environments have potential for recreational and educational use as in situ laboratories and demonstration centers, where benefits of conserving urban biodiversity can be communicated.
\end{abstract}

Keywords: abandoned quarries, aquatic macroinvertebrates, biodiversity, Karura forest, Nairobi City

\section{Introduction}

In an endeavour to meet societal needs, humans have transformed a significant percentage of natural landscapes into anthropogenic biomes (Ellis and Ramankutty 2008). During the past 50 years, humans have converted natural ecosystems more rapidly and extensively than any other comparable period in human history (WHO 2005). Ellis and Ramankutty (2008) observed that $75 \%$ of the earth's ice-free lands show evidence of human alteration, with less than a quarter remaining as wild lands and supporting only $11 \%$ of the global terrestrial primary production. Consequently, a significant portion of the earth's natural landscapes have been lost or degraded (Hoekstra et al. 2005); though with moderate gains in human wellbeing and economic development (WHO 2005). Currently, there are many efforts being made to curb environmental degradation and restore degraded landscapes, in order to maintain their capacity to support biodiversity and associated ecological processes; hence provide ecosystem goods and services (Higgs 1997; WHO 2005).

Some evidence of human exploitation of natural resources and transformation of landscapes are abandoned excavations or quarries, which result from harvesting of soil, sand and stones. These materials are used for infrastructural development in urban and semi-urban areas. Generally, the excavations made are rarely rehabilitated and, as a result, water from surface run-off or underground seepage accumulates to form an artificial wetland. Usually, these artificial wetlands are inhabited by frogs and they also act as breeding areas for mosquitoes. When near human dwellings, wetlands can be very unpopular with surrounding communities, who regard them as hazardous areas where accidents are likely to occur (Macharia et al. 2010). Dumping of solid waste and domestic effluent into wetlands is a common and widespread practice, primarily as a result of inadequate awareness of wetland values and weak enforcement of solid waste management regulations in Kenya (NEMA 2011).

However, undisturbed and permanently flooded abandoned quarries can evolve over time to acquire similar characteristics as natural wetlands though they are rarely considered during national wetland inventories and assessment studies (Macharia et al. 2010; MEMR 2012). A period of ten years has been reported as being sufficient for an artificial wetland to develop some fundamental 
features of natural wetlands (Ruhi et al. 2012). Abandoned quarries tend to be small to medium-sized, ranging in size from 0.1 ha to 10 ha (Semlitsch and Bodie 1998; Semlitsch 2000). Because of their small sizes, they are seldom captured on land use/cover or satellite maps (Roeck et al. 2008), inventoried and documented (Hughes and Hughes 1992). Their occurrences and distribution in many countries remain unknown.

Artificial wetlands, such as abandoned quarries, can be important for biodiversity conservation in urban areas. They can also be useful to the local community for water storage, floodwater retention, recreation, education and research (Oertli et al. 2005). The fact that these ecosystems provide both feeding and breeding habitat for diverse and significant numbers of plant and animal species (Ng'weno 1992; Ruhi et al. 2012), justifies their consideration and inclusion in future wetland inventory and assessment studies. More importantly, small wetlands have been found to be important in maintaining regional biodiversity, particularly of species with limited dispersal abilities, such as amphibians and mollusks (Semlitsch and Bodie 1998). The presence of several ecologically healthy, though isolated, small wetlands in different locations in a landscape has been found to be important refuges for displaced species or act as stop-over sites for migratory species of birds and invertebrates (Semlitsch 2000). Indeed, species inhabiting different locations in a landscape are capable of interacting through dispersal and migration processes and ultimately maintain high biological diversity by a process known as 'source-sink' dynamics (Hanski 1998).

Studies of small artificial wetlands will increase our understanding on their ecosystem functions and processes, which can then be used to inform their sustainable management, as stipulated in the Ramsar Convention (Ramsar 2010). Data gathered are important as it can be used in guiding valuation of benefits derived from wetland ecosystem services (Groot et al. 2006), which range from ecological, socio-cultural to economic values (Higgs 1997; Hansson et al. 2005). Meanwhile ecological data can be used to predict the succession stages and progression in wetlands after disturbance. Ruhi et al. (2012) proposed three succession stages of disturbed or newly created wetlands, each with typifying species. The early stage is dominated by taxa with short life cycles and active dispersal mechanisms. The intermediate stage of wetland development is dominated by filter feeders, whereas the climax stage is dominated by species with longer life cycles. This is the stage at which species community in disturbed or artificial wetlands resemble those found in natural wetlands. In this study, we present preliminary inventory and assessment findings of an artificial wetland, the Lily Wetland located in Karura Forest, north of the city Nairobi in Kenya. First, the study mapped the Lily Wetland, followed by determination of water physical and chemical characteristics, vegetation, birds, and macroinvertebrates, fish and amphibian communities. The ecological data generated were used to assess the environmental condition of the wetland by comparing the data with those from natural wetlands, to determine the extent to which the Lily Wetland has developed to resemble a tropical natural wetland.

\section{Materials and methods}

\section{Physical description of the Lily Wetland}

The Lily Wetland is located in Karura Forest, (1¹4.535' S, $36^{\circ} 49.081^{\prime}$ E) in Nairobi County, Kenya. The wetland measures approximately 0.25 ha in area during the two-dry periods (February and March; August to October) and slightly more than 0.45 ha when flooded during the two-rainy season (April to June and November to January). It is one of the permanent artificial wetlands found in the forest and receives most of its water in the form of surface runoff from the surrounding forest catchment and underground seepage. The wetland developed on an abandoned quarry and has been in existence since the early 1990s. Karura Forest has an area of 1041 ha and comprises one of the largest of three gazetted forest blocks in Nairobi County. The others are Ngong and Ololua forests. Karura Forest is situated in the north-western part of Nairobi County and borders the high-end suburbs of Muthaiga, Gigiri, Runda, and Ridgeway, as well as the medium income estates of Mathare North, Highridge and Spring Valley. The western part of the forest is also known as Sigiria forest. Karura and the other forests in Nairobi County are remnants of the original dense upland dry forest that once covered Nairobi area before the onset of urbanisation in the early 1900s. Karura Forest acts as a subcatchment for several streams, including Thigirie, Gitathuru, Ruiruaka and Karura, which all feed into the Nairobi River. The Lily Wetland is accessible by walking along a $40 \mathrm{~m}$ trail from the main road. A comparison was made between a nearby natural wetland, Kentmere $\left(1^{\circ} 9.649^{\prime} \mathrm{S}, 36^{\circ} 43.716^{\prime} \mathrm{E}\right)$ and the Lily Wetland, to evaluate the degree to which the Lily Wetland has naturalised. This natural wetland was 0.5 ha in area and was located approximately $15 \mathrm{~km}$ from the Lily Wetland. A once-off sampling of Kentmere was undertaken in September 2016 using the same protocols used for water and biological data collection of the Lily Wetland to allow for comparison.

\section{Wetland mapping and water quality}

The Lily Wetland was located using coordinates obtained from Google Earth Pro maps. The size of the wetland was determined by first making a polygon sketch map along the wetland margins on Google satellite image, using the polygon tool in Google Earth Pro. The wetland perimeter was estimated and used to calculate the wetland area (Britt et al. 2015). Changes in surface area of the Lily Wetland between 2003 and 2017 were determined and compared between dry and wet seasons. In both cases, wetland surface area were taken at the end of each season, with wet seasons measured made for the months of December and January whereas months considered for dry seasons were March and October. For each season, seven maps were made depending on their availability on Google Earth Pro. Water depth measurements were taken from eight different points within the wetland using a graduated wooden pole. Mean depth was computed and used to determine the volume of water in the wetland (Masser and Jensen 1991). In addition, several water quality parameters were measured, among them dissolved oxygen, which was determined using an iodometric method (Koenings et al. 1987). Water samples were collected with tightly closing 
$300 \mathrm{ml}$ glass bottles, the dissolved oxygen fixed at the site and samples transported in iced cooler box for analysis in the Hydrobiology Laboratory of the University of Nairobi. Water temperature was measured at different depths in the wetland using pocket thermometer (H Guru, GGSBT 5), whereas water $\mathrm{pH}$ was measured using a $\mathrm{pH}$ metre (Hanna, Combo 98180) and turbidity was measured using a standard Secchi disk.

\section{Assessment of plant and animal communities}

Plant and animal communities were intensively sampled twice, in March 2012 and again in September 2016. The second sampling period was intended to enrich existing data on aquatic macroinvertebrates from the Lily Wetland. In the Lily Wetland, vegetation was sampled from five $10 \mathrm{~m}$ transects running from the wetland edge at angle of $90^{\circ}$ towards the centre or open water. Along each transect, vegetation was sampled in 1- $\mathrm{m}^{2}$ quadrats, $2 \mathrm{~m}$ apart from one another. The number of individuals of each plant taxon was counted for each quadrat and the data are presented as total counts or abundances (Bullock 2013). All plants found in the wetland (submerged, emergent and floating) and in the margins were collected and identified in the herbarium of the University of Nairobi.

The faunal component was sampled according to broad taxonomic groups, including birds, fish, amphibians and aquatic macroinvertebrates. Bird species data were collected using the listing methods (Gibbons and Gregory 2013), a method appropriate for this area considering it is relatively small and possible to enumerate all wetland bird species. Fish samples were taken using a hand-held scoop nets at five sites next to the transects in the littoral zones close to areas where vegetation were sampled (Côté and Perrow 2006). This method is suitable for small fish in shallow waters. Amphibians were sampled using both scoop nets and opportunistic study method (Halliday 2013). Fish and aquatic macroinvertebrate samples were taken close to sites where vegetation was sampled using $0.5 \mathrm{~mm}$ mesh ponds nets (Murkin et al. 1994). Fish, amphibian and macroinvertebrate samples were collected from the water column and bottom of the wetland, as well as in both emergent and submerged macrophytes. Samples were sorted in the Wetland Laboratories of University of Nairobi and National Museums of Kenya. Specimens were identified morphologically to the lowest practical taxonomic level using standard identification guides for macroinvertebrates (Merritt et al. 2008), vegetation (Agnew 2013), birds (Zimmerman et al. 2005), fish (Nyingi 2013) and amphibians (Channing and Howell 2006).

\section{Recreational and education importance}

Information on the benefits of Karura Forest to visitors was gathered through the administration of structured questionnaires (see Appendix). The respondents were asked to rate the importance of the five major resources available in the forest: walking trails, forest, wetlands, playing fields, and restaurants. Specifically, each respondent was requested to rate the importance of the Lily Wetland as a centre of learning about nature and environment, scenery and aesthetic value, and engaging in recreational activities. Thirty-four adult visitors were randomly sampled during seven days in September 2016 (Monday to Sunday). The key focus of the questionnaire was to assess the importance of the small wetlands in Karura as potential recreational and educational sites, as well as for tourism. All visitors paid US\$1 each to enter Karura Forest per day. For each question, the respondents were requested to rank the importance of each attribute using Likert scale with most important given a score of five, whereas the least important was allocated a score of one (Likert 1932).

\section{Data analyses}

A checklist of studied organisms found in the Lily Wetland was compiled and enumerated. The water quality and biodiversity data were analysed using descriptive statistics. The persistence, existence and evolution of the Lily Wetland for the past 15 years were manually assessed from maps obtained from the Google Earth Pro and the changes in wetland area calculated for the past 15 years and then compared between dry and wet seasons using unpaired $t$-tests. Socioeconomic data were analysed using descriptive statistics of means, standard deviations and later compared using paired $t$-test and significance differences accepted at $p=0.05$.

\section{Results}

\section{Area and persistence of the Lily Wetland}

Analyses of the Lily Wetland size data for the past fifteen years (from 2003 to 2017) showed that at no point in that time did the wetland dry out, but its size fluctuated in response to wet and dry seasons (Figures 1 and 2). During the past 15 years its size ranged from $0.29 \pm 0.03$ to $0.36 \pm$ 0.06 ha and the wetland was markedly larger at the end of wet seasons, especially during the months of December and January, but smaller at the end of prolonged dry spells, especially during months of March and October $(p=0.03$, $t=2.55$, df $=12$ ). Mean water depth during this study was $1.29 \pm 0.74 \mathrm{~m}(n=8)$ and the total water volume was calculated as approximately $3340 \mathrm{~m}^{3}$.

\section{Water physical and chemical measurements}

The $\mathrm{pH}$ of the water in the Lily Wetland ranged between 7.5 and $7.8(n=5)$. Dissolved oxygen (DO) measurements displayed interesting trends. Dissolved oxygen readings made at the deeper parts $(>1 \mathrm{~m})$ of the wetland ranged between 8.7 and $9.0 \mathrm{mg} \mathrm{l}^{-1}$, with a mean of $8.7 \pm 0.1 \mathrm{mg} \mathrm{l}^{-1}$ $(n=3)$ and those taken in shallower areas $(<1 \mathrm{~m})$ had a mean of $8.0 \pm 0.03 \mathrm{mg} \mathrm{l}^{-1}(n=3)$ and ranged from 7.9 to $8.0 \mathrm{mg} \mathrm{l}^{-1}$. Likewise mean water temperature showed similar trends, with the mean surface water temperature being higher for the shallow waters $\left(27.9 \pm 0.6{ }^{\circ} \mathrm{C}, n=8\right)$ and lower in deep waters $\left(22.8 \pm 0.5{ }^{\circ} \mathrm{C}, n=8\right)$. Water transparency had a mean of $22 \mathrm{~cm}(n=4)$, but ranged from $20 \mathrm{~cm}$ in the littoral zone to $26 \mathrm{~cm}$ in the deeper open sites. The maximum water depth was $3.5 \mathrm{~m}$ deep, but the maximum accessible depth was $1.7 \mathrm{~m}$.

\section{Floral diversity}

A total of 12 plant species associated with the wetland was identified during this study and classified into four categories depending on the habitat they occupied (Figure 

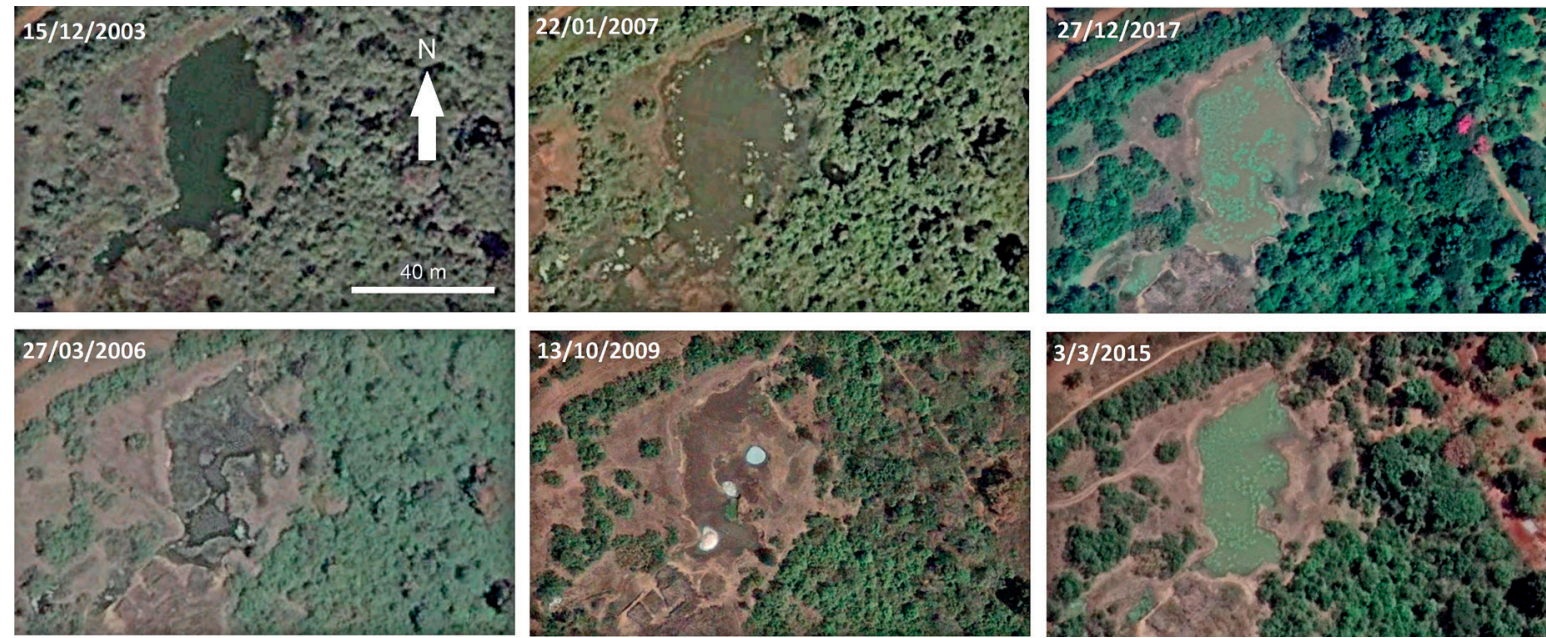

Figure 1: Representatives of Google Earth Pro images of the Lily wetland during wet seasons (upper panel) and dry seasons (lower panel). Embedded on each image is the date the image was obtained. Months representing wet seasons (April to June and November to January) and dry seasons (February and March; August to October)

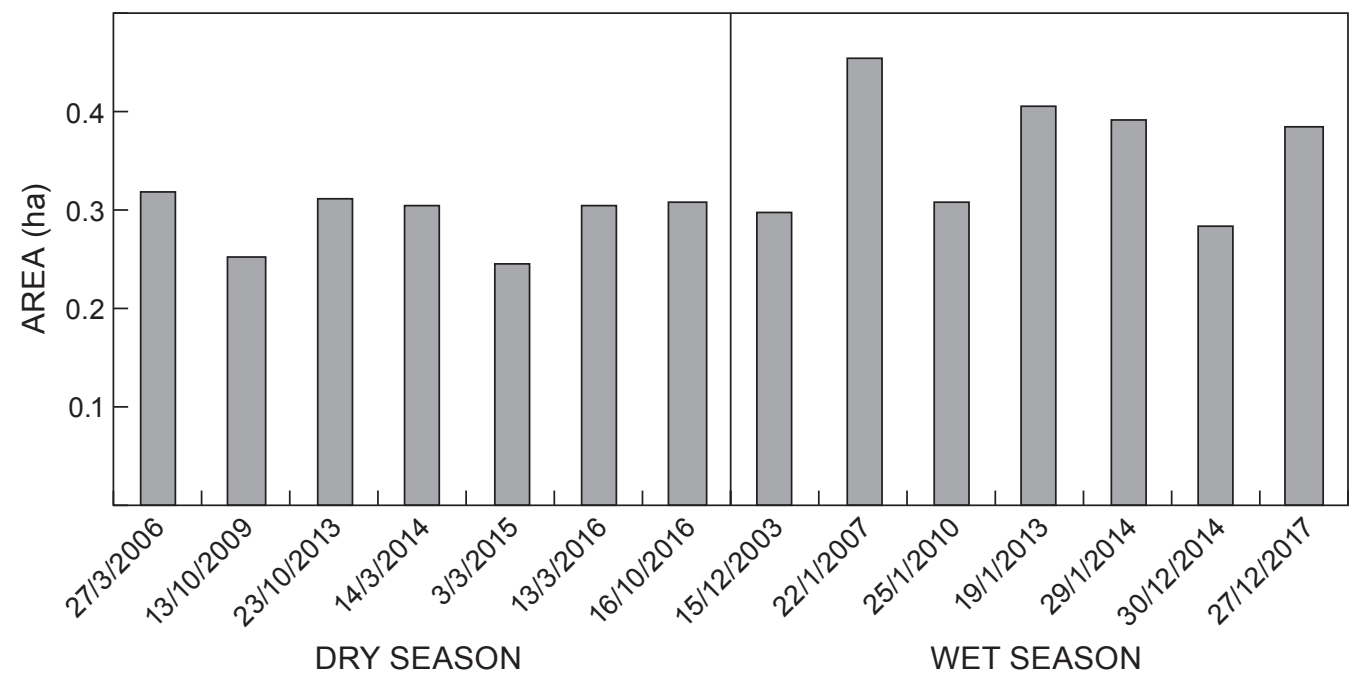

Figure 2: Calculated areas of the Lily wetland using Google Maps between 2003 and 2017 during wet seasons (April to June and November to January) and dry seasons (February and March; August to October). Wetland surface area was taken at the end of each season, with wet seasons (December and January) and dry seasons (March and October)

3). Submergent and floating categories were each represented by one species Potamogeton sp. and Salivinia molesta, respectively. Emergent plants were represented by three species of Cyperus papyrus, Cyperus immensus and Nymphaea nouchali, whereas seven plant species were sampled on the edges of the wetland. The dominant edge species were Brachiaria eruciformis, Sesbania sesban, Adenia gummifera, Typha domingensis and Ludwigia sp., whereas hydrophilous grasses, such as Setaria sp. and Cynodon dactylon, as well as Cyperus papyrus sedges, were occasionally present. The landscape bordering the Lily Wetland was sparsely vegetated by both herbaceous and woody plant species. Common plant species were grasses, especially, Panicum maximum and Setaria sp., terrestrial sedges growing on moist soil, such as Cyperus rotundus, and succulents characterised by Kalanchoe sp., as well as terrestrial herbs, such as Phyllanthus amarus. Woody plant species were scattered around the wetlands and included bushes of Adenia gummifera, Jasminum fluminense, Rhus natalensis, Rhus vulgaris, Lantana camara, Euclea divinorum, Ocimum kilimandscharicum, Scolopia zeyheri and Alysicarpus rugosis. Two of the plant species were invasive and alien to Kenya: the floating aquatic water fern Salivinia molesta; and the woody Lantana camara.

\section{Faunal diversity}

Twelve families from six orders and fifteen taxa of aquatic macroinvertebrates were found in the Lily and Kentmere wetlands (Table 1). The number of taxonomic groups (11 taxa) found in the Lily Wetland were similar to those 


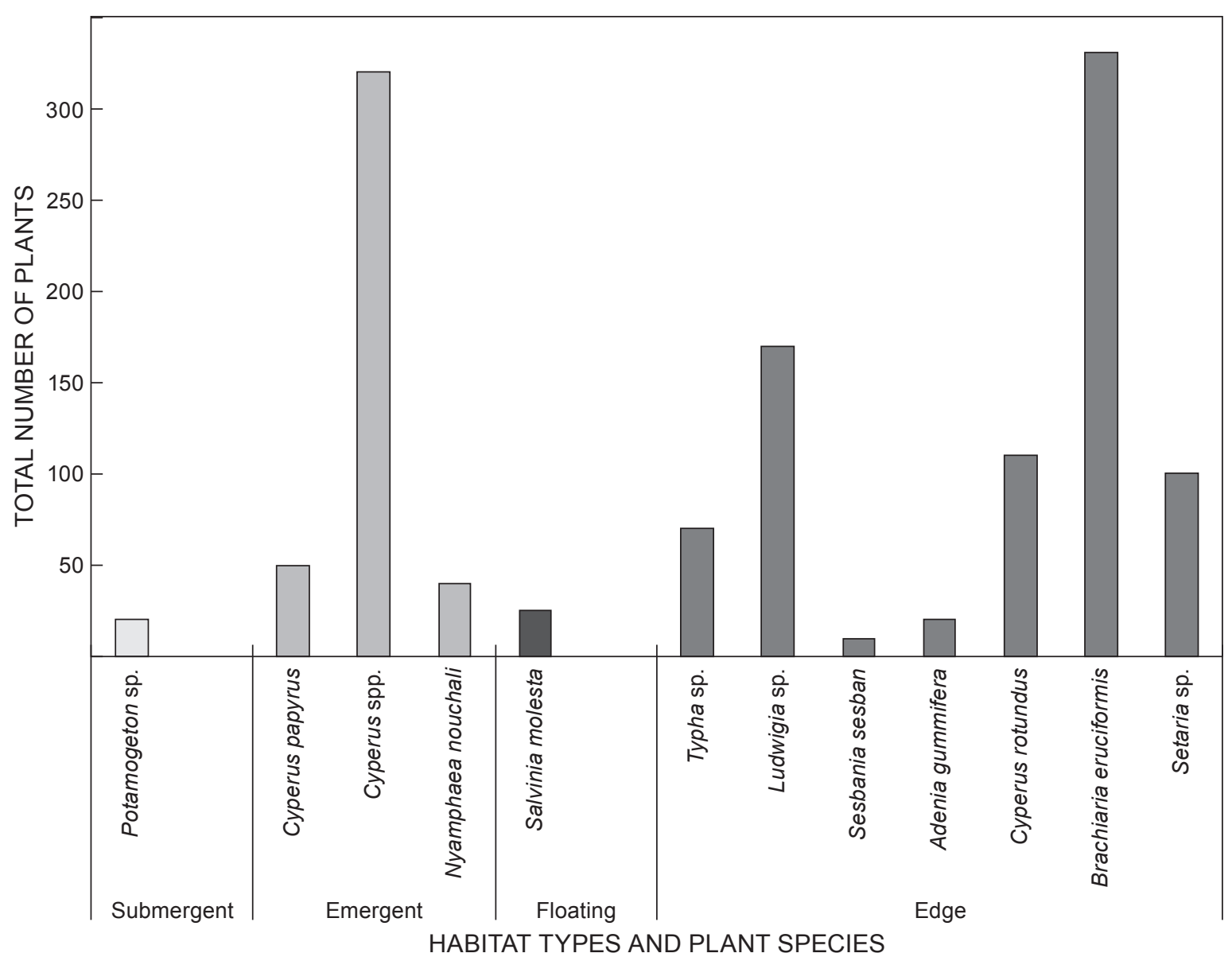

Figure 3: Abundances (total counts) of wetland plants sampled during the study in the Lily wetland in March 2012. Abundance refer to total number of individual plants pooled from all quadrats in all the ten transects

Table 1: Aquatic macroinvertebrates richness and abundances sampled during the two periods in the Lily and Kentmere wetlands

\begin{tabular}{|c|c|c|c|c|c|}
\hline \multirow[b]{3}{*}{ Order } & \multirow[b]{3}{*}{ Family } & \multirow[b]{3}{*}{ Taxon/Species } & \multicolumn{3}{|c|}{ Sampling periods and number of macroinvertebrates } \\
\hline & & & \multirow{2}{*}{$\begin{array}{l}\text { March } 2012^{*} \\
\text { Lily wetland }\end{array}$} & \multicolumn{2}{|c|}{ September 2016} \\
\hline & & & & Lily wetland & Kentmere wetland \\
\hline \multirow[t]{8}{*}{ Coleoptera } & Dytiscidae & Bidessus sp. & 6 & 1 & 4 \\
\hline & & Copelatus sp. & & & 2 \\
\hline & & Laccophilus sp. & & 1 & \\
\hline & & Rhantus sp. & & & 2 \\
\hline & Hydrophilidae & Berosus sp. & & & 2 \\
\hline & & Helochares sp. & 19 & & 18 \\
\hline & & Regimbartia sp. & & 2 & \\
\hline & Scirtidae & & & & 12 \\
\hline \multirow[t]{2}{*}{ Diptera } & Chironomidae & & & & 12 \\
\hline & Culicidae & Culex sp. & & & 1 \\
\hline Ephemeroptera & Baetidae & Cloeon sp. & & 33 & \\
\hline Gastropoda & Lymnaeidae & Lymnaea sp. & 1 & 44 & \\
\hline \multirow[t]{3}{*}{ Hemiptera } & Belostomatidae & Sphaerodema nepoides & 53 & 2 & 8 \\
\hline & Nepidae & Ranatra sp. & & 1 & \\
\hline & Notonectidae & Anisops sp. & & 8 & \\
\hline \multirow[t]{2}{*}{ Odonata } & Aeshnidae & Anax imperator & 22 & 13 & \\
\hline & Coenagrionidae & Pseudagrion sp. & & 15 & 2 \\
\hline Abundance & & & 101 & 120 & 63 \\
\hline Number of taxa & 12 & 15 & NA & 11 & 10 \\
\hline
\end{tabular}

* Indicates samples collected in March 2012 that were only identified up to order and family levels and their presentation here is just for general comparison. NA = not applicable. 
found in Kentmere (10 taxa), but there were remarkable differences in abundances, with Lily having higher abundance (120) versus Kentmere's 63 individuals during the same period. Species composition between the two wetlands was comparable at order and family levels, but showed remarkable differences at genus and species levels. Only three species were shared at genus and species levels and these were Sphaerodema nepoides, Pseudagrion sp. and Bidessus sp. The abundance of aquatic macroinvertebrates (101 individuals) recorded during the March 2010 sampling period was comparable to the 120 individuals obtained in September 2016 within the Lily Wetland. Four species of wetland birds were recorded, including the Egyptian goose Alopochen egyptiacus with two individuals, Yellow-billed duck Anas undulate (5), African black duck Anas sparsa (7), and Grey heron Ardea cinerea (1). The thirty-six individuals of small fish sampled in the Lily Wetland were the Guppy Poecilia reticulata, an exotic fish species, which was introduced in Kenyan wetlands to control mosquito larvae. This fish species was probably introduced into the wetland through natural dispersal of fish eggs by birds from nearby wetlands. Meanwhile, six individuals of common reed frogs Hyperolius viridiflavus and approximately 150 unidentified tadpoles were opportunistically collected from the Lily Wetland.

\section{Recreation and education importance of the Lily Wetland}

A total of 34 respondents were interviewed during this study and they comprised 22 adult males and 12 adult females. Seventeen of the respondents interviewed had at least university education, 12 had college education, with two having secondary education. Fourteen respondents visited Karura Forest with friends, eight as part of educational groups, and seven with their families, whereas five came alone. The duration of stay ranged from less than two hours (five respondents), three to five hours (18) and six to eight hours (11 respondents). Twenty-four respondents gave recreation as the main reasons for visiting Karura Forest, whereas ten gave education.

The forest was ranked highly as the major attraction for those who visit Karura, with mean score of $4.18 \pm 0.67$ ( $n=34$ ); followed by walking along the trails (4.09 \pm 0.67 ), a visit to the wetlands $(3.76 \pm 0.82)$, and using playing fields $(3.44 \pm 1.02)$. The restaurants were of reasonable quality for middleclass urban customers, but ranked lowest $(2.15 \pm 1.02)$, as a reason for visiting Karura Forest (Figure 4a). Comparisons of normalised benefit mean scores of respondents using $t$-test showed that ranking was significantly different for some of the benefits (Table 2). Furthermore, The Lily Wetland was highly rated by the respondents for aesthetic features $(4.29 \pm 0.63)$ and as a site for learning about nature and natural environment (3.88 \pm 0.69). The Lily Wetland is small, and use of its resources was strictly restricted, it was therefore not considered to be an important site for recreational activities $(3.85 \pm 0.96)$ (Figure 4b). Analyses of transformed data in the paired $t$-test found that appreciation for the scenery was significantly greater in respondents views than its use for learning about nature and natural environment $(t=2.36, p=0.02)$ and as a place to engage in recreational activities $(t=2.32, p=0.03)$.

\section{Discussion}

The environmental and biodiversity data compiled for the Lily Wetland show that artificial wetlands, such as abandoned quarries, can evolve over time and acquire characteristics similar to those of natural wetlands. The Lily Wetland supported biological communities of water dependent species, such as macroinvertebrates, macrophytes, birds, fish and amphibian communities that generally resembled those of natural wetlands, such as Kentmere found in Kiambu County. Despite its small size, the Lily Wetland has become a permanent feature in Karura Forest, having persisted for more than fifteen years without drying-up, which was demonstrated by its capacity to store water during the wet and dry seasons, support aquatic organisms that are water dependent, and its potential to act as an educational and recreational site, because of the existing wetland biodiversity.

Wetland plants recorded in the Lily Wetlands have been recorded in other small wetlands of Kenya and Tanzania (Alvarez et al. 2012), as well as other studies conducted to draw comparisons between artificial and natural wetlands in other parts of the world (Efitre et al. 2001; Lundkvist et al. 2002; Ruhi et al. 2012). For instance, four true wetland plants species recorded, including the submergent (Potamogeton spp.), floating (Salivinia molesta) and emergent species of Cyperus papyrus and Typha sp. The animal community was represented by 11 taxa of aquatic macroinvertebrates whose composition and abundance were comparable to the community found in Kentmere, a natural wetland, which had 10 taxa. Whereas aquatic macroinvertebrates were generally similar at order and family levels, there were minor differences at the genus and species levels, with only three taxa out of 15 being shared between the Lily and the Kentmere wetlands. Macrophytes and macroinvertebrates recorded in the Lily Wetland have also been recorded in other natural small to medium-sized wetlands found in East Africa, such as Hannington, Fielding and Murchison Bays (Sekiranda et al. 2004), Lake Nabugabo (Efitre et al. 2001) in Uganda as, well as small wetlands in Kenya's Lake Victoria Basin (Muli 2005). Noticeably macroinvertebrate studies in small to medium-sized open wetlands have seldom been carried out in Kenya and the whole of East African wetlands in general (Talling 2011).

The dissimilarity in species compositions observed between the Lily and the Kentmere wetlands was taken with some degree of caution, because each wetland could be subject to different ecological factors, and be at a different succession stage, which were not considered during this study. According to Ruhi et al. (2012), biological traits and community structure of macroinvertebrates can be used to assess the development and succession stages of artificial wetlands and also determine how far they are from resembling a natural one. For instance the presences of several individuals of aquatic beetles Helochares spp. and Bidessus spp. were a good indication that the macroinvertebrate community in the Lily Wetland was at a more advanced phase of development (Ruhi et al. 2012). Coleopteran beetles require longer time to establish and form mature assemblages. During the 20 years that the Lily Wetland had been in existence was sufficient for Coleopteran assemblages to have established. In addition, 


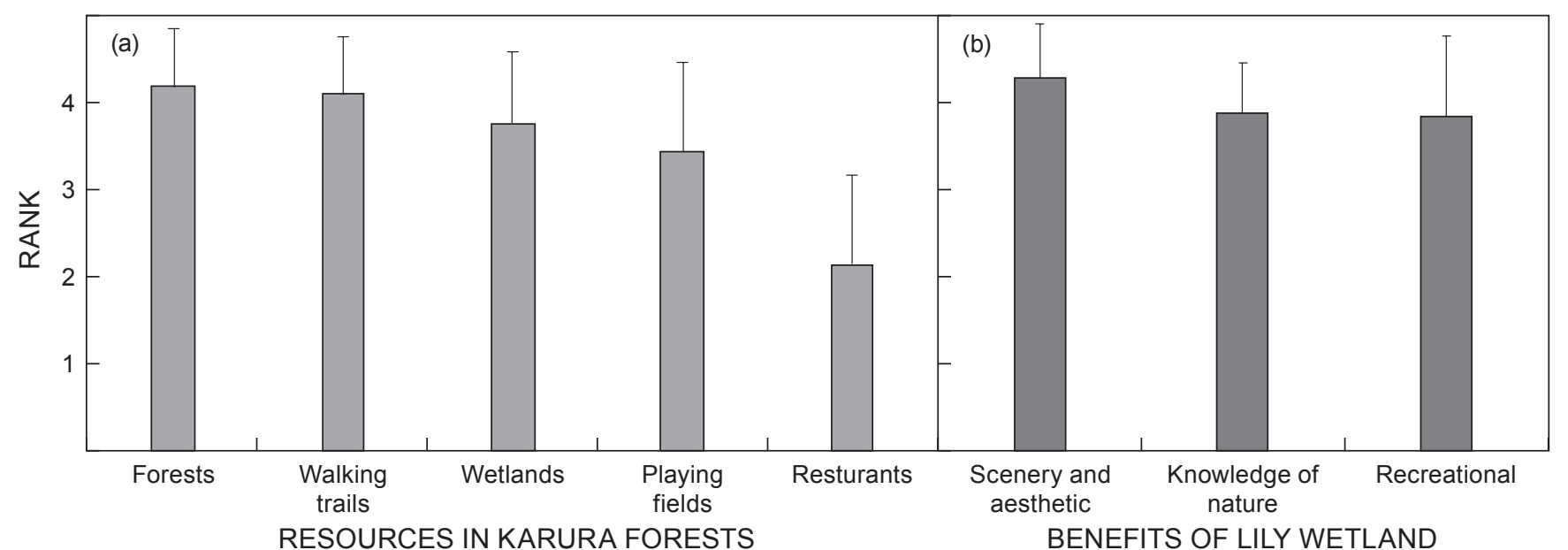

Figure 4: (a) shows the importance of Karura forest and (b) the benefits obtained from the Lily wetlands. Bars on the graphs represent standard deviations, with $n=34$

Table 2: Paired t-test results on the comparison of benefits (recreational, educational) obtained in the Lily wetland by visitors visiting Karura Forests. Significant differences between benefits were accepted at $p<0.05$

\begin{tabular}{lcccc}
\hline & Forest & $\begin{array}{c}\text { Walking } \\
\text { trails }\end{array}$ & Wetlands & $\begin{array}{c}\text { Playing } \\
\text { fields }\end{array}$ \\
\hline Walking trails & 0.58 & & & \\
Wetlands & 0.01 & 0.11 & & \\
Playing fields & 0.00 & 0.00 & 0.18 & \\
Restaurants & 0.00 & 0.00 & 0.00 & 0.00 \\
\hline
\end{tabular}

Coleoptera species are known to be specialist species that require environmental stability, arriving after pioneer generalist colonisers and only occur in non-impacted wetlands or natural sites (Lundkvist et al. 2002).

Many questions have been asked about the importance of studying and conserving small wetlands (Kamp and Hayashi 1998; Smelitsch and Bodie 1998; Smelitsch 2000). Information generated by this study strongly supports inventory and prudent management of these ecosystems, because of the socio-economic and ecological roles they play in the environment. The Lily Wetland stored water of an acceptable quality, as is demonstrated by the physical characteristics measured and the presence of characteristic wetland species of macroinvertebrates, fishes, birds, amphibians and macrophytes. Smelitsch and Bodie (1998) noted that small and isolated wetlands in USA were likely to continue being lost, because of inadequate biological data, and appreciation of their ecosystem values. In order to avoid that situation, they strongly advocate for formulation of legislation to support conservation of the seemingly unimportant wetland ecosystems. Using data from the south-eastern Atlantic coastal plain in USA, Smelitsch and Bodie (1998) found that majority of small wetlands were rich in amphibian species, which contributed to maintaining species diversity both at local and regional levels through dispersal and migration under the source-sink mechanisms or metacommunity dynamics. In addition to storing water, small wetlands are also focal points of groundwater recharge, an important consideration in the development of wetland conservation policies (Kamp and Hayashi 1998).

One of the unique characteristics used to designate areas as wetlands are their capacities to exist and persist over several seasons (RAMSAR 2010). Apart from being a permanent feature in Karura Forest, the Lily Wetland is currently an important ecosystem, being considered during planning and management of the forest, because of its aesthetic and recreational properties (KFS 2013). Meanwhile just like other small-sized wetlands throughout the country, the Lily Wetland is not mapped and inventoried and its existence continues to be ignored despite the fact that it has existed for more than 15 years. The current efforts to map wetlands in Kenya primarily rely on remote sensing imagery (Landsat and Envisat; MEMR 2012), with minimal ground surveys and local knowledge to verify their occurrence. Unfortunately, remote sensing methods can only capture ecologically relevant data of larger wetlands (Roeck et al. 2008). Ground-truthing surveys after a remote sensing study can add up to $88 \%$ more wetlands present in an area that could not be detected by remote sensing analyses, because of their small size. Consistent with this study, any attempt to map out small-sized wetlands must be accompanied by ground-truthing surveys and complemented by very high spatial resolution images, such as those found on Google Earth Pro maps, as well as other versions, including IKONOS images for optical studies, RADARSAT-1 and 2 (Roeck et al. 2008). Other than locating and mapping wetlands, local knowledge can be useful in inquiring about their ecological and socio-economic significance (Macharia et al. 2010). Using Google Earth Pro maps and ground-truthing it was possible to capture important ecological information, including wetland size changes for the past fifteen years, as well as its capacity to support vegetation and store water.

From the above review, it is clear that current knowledge and understanding of the importance of small wetlands is limited not only in Kenya, but also in the whole of East Africa (Alvarez et al. 2012). The recently produced atlas of the 
Kenyan wetlands placed more emphasis on larger wetlands and paid little attention to small and isolated wetlands in agricultural landscape and in forest reserves, such as the Lily and Kentmere wetlands (MEMR 2012). This situation arose as a result of overreliance on satellite images and topographic maps, which are known to overlook small wetlands (Roeck et al. 2008). This study acknowledges that mapping of small wetlands will require expertise and time, but the fact that it is possible to locate these wetlands using local knowledge and Google Earth Pro maps calls for concerted efforts by government to support such initiatives. Majority of small wetlands are found as remnants in modified agricultural or mined landscapes, where the adverse impacts of humans are high conservation interventions are difficult to implement due complexes of controlling improper land use practices in private lands (Macharia et al. 2010). The existing wetland assessment and monitoring strategy for Kenya (NEMA 2012), which is a domesticated version of the RAMSAR Convention, Strategy 1.1 of the Strategic Plan for the period 2009-2015, advocates for description, assessment and monitoring of the extent and condition of all types of wetlands at relevant scales, in order to inform and underpin implementation of the Convention, in particular the application of its provisions concerning the wise use of all wetlands (RAMSAR 2010). This is a positive development and the implementation of strategy would significantly improve our knowledge of wetland ecosystems and inform management decisions at local and national levels.

\section{Educational and recreational potential of small wetlands}

The findings of this study indicate that small wetlands within protected areas can be valuable assets for education, recreation and tourism. The Lily Wetland in Karura Forest was ranked favourably as an attractive site, because of its aesthetic features and animal-plant interactions. Visitors considered it valuable for learning and interacting with nature and natural environment, especially for the urban families and their children. These findings were interesting and consistent with the current management approaches in which the Lily Wetland has become an important feature of Karura Forest, including being considered during design and establishment of recreational and educational areas. The Nairobi City County has a population of 4.5 million people (GoK 2019), which is putting huge pressure on the land, water and the environment, in general. There is clear evidence of serious environmental degradation in different parts of the city. Restoration of the environment must be undertaken if the clean and safe environment goal for all citizens is going to be achieved as envisioned in Vision 2030 (GoK 2007). This policy document aims to transform the country into middle-income status and providing high quality life to all its citizens by the 2030. Indeed, this study has shown that it is possible to improve the quality of life of citizens in Nairobi City by conserving existing natural areas, including natural forests and small wetlands, such as the Lily Wetland. Urban biodiversity, including the modified ecosystems and the wild species that they hold, is valuable both from ecological, economic and social stand points. It should therefore be conserved, monitored and planned for in the integrated development plan for all urban environments.
Acknowledgements - We thank the Kenya Forest Service for allowing us to carry out this research in the Karura Forest. We appreciative the reviews by two anonymous reviewers, as well as the editors of the journal, who were kind and patient and gave constructive criticism that greatly helped to improve our manuscript.

\section{ORCID}

GG Ndiritu (iD https://orcid.org/0000-0001-6237-5287

\section{References}

Agnew AD. 2013. Upland Kenya wild flowers and ferns: a flora of the flowers, ferns, grasses, and sedges of highland Kenya. Nairobi, Kenya: Nature Kenya - The East Africa Natural History Society.

Alvarez M, Becker M, Böhme B, Handa C, Josko M, Kamiri HW, et al. 2012. Floristic classification of the vegetation in small wetlands of Kenya and Tanzania. In: Vegetation databases for the 21st century. Biodiversity and Ecology 4:63-76.

Britt K, McGee J, Campbell J. 2015. An Introduction to Google Earth Pro. Virginia, USA: Virginia Tech Geospatial Extension Program, Department of Forest Resources and Environmental Conservation.

Bullock JM. 2013. Plants. In: Ecological census techniques. Sutherland WJ (Ed.). Cambridge, United Kingdom: Cambridge University Press.

Channing A, Howell KM. 2006. Amphibians of East Africa. Frankfurt-am Main, Germany: Edition Chimaira Press.

Côté IM, Perrow MR. 2006. Fish. In: Sutherland WJ (Ed.). Ecological census techniques. 2nd Ed. Cambridge, United Kingdom: Cambridge University Press.

De Roeck ER, Verhoest NE, Miya MH, et al. 2008. Remote sensing and wetland ecology: a South African case study. Sensors (Basel) 8: 3542-3556.

Efitre J, Chapman, LJ Makanga, B. 2001. The inshore benthic macroinvertebrates of Lake Nabugabo, Uganda: seasonal and spatial patterns. African Zoology 36(2): 205-216.

Ellis, EC, Ramankutty N. 2008. Putting people in the map: anthropogenic biomes of the world. Frontiers in Ecology and the Environment 6: 439-447.

Gibbons DW and Gregory RD. 2006. Birds. In: Sutherland WJ (Ed.). Ecological census techniques. 2nd Ed. Cambridge, United Kingdom: Cambridge University Press.

GoK (Government of Kenya). 2007. Kenya Vision 2030. Nairobi, Kenya: Government of Kenya.

GoK (Government of Kenya). 2019. Population distribution by Counties and sex. Nairobi, Kenya: Central Bureau of Statistics.

Groot R, Stuip M, Finlayson M, Davidson N. 2006. Valuing wetlands: Guidance for valuing the benefits derived from wetland ecosystem services. Ramsar Technical Report No. 3/CBD Technical series No. 27. Gland, Switzerland: Ramsar Convention Secretariat.

Halliday T. 2013. Amphibians. In: Ecological census techniques. Sutherland WJ (Ed.). Cambridge, UK: Cambridge University Press.

Hanski I. 1998. Metapopulations dynamics. Nature 396: 41-49.

Hansson LA, Brönmark C, Anders Nilsson P, Åbjörnsson K. 2005. Conflicting demands on wetland ecosystem services: nutrient retention, biodiversity or both. Freshwater Biology 50: 705-714.

Higgs S. 1997. What is good ecological restoration? Conservation Biology 11: 338-348.

Hoekstra JM, Boucher TM, Ricketts TH, Roberts C. 2005. Confronting a biomass crisis: global disparities of habitat loss and protection. Ecology Letters 8: 23-29.

Hughes RH and Hughes JS. 1992. A directory of African wetlands. Gland, Switzerland: IUCN and Cambridge, United Kingdom: UNEP/WCMC. 
Kamp G, Hayashi M. 1998. The groundwater recharge function of small wetlands in the semi-arid Northern Prairies. Great Plains Research 8: 39-56.

KFS (Kenya Forest Service). 2013. Karura Forest, Kenya. www. kenyaforestservice.org. [Accessed 21 February 2013].

Koenings JP, Edmundson JE, Kyle GB, Edmundson JM. 1987. Limnological field and laboratory manual: Methods for assessing aquatic production. Report Series 71. Juneau, Alaska, United States: Alaska Department of Fish and Game (Fisheries Rehabilitation Enhancement and Development Division).

Likert R. 1932. A Technique for the Measurement of Attitudes. Archives de Psychologie 140: 1-55.

Lundkvist E, Landin J, Karlsson F. 2002. Dipersing diving beetles (Dytiscidae) in agricultural and urban landscapes in south-eastern Sweden. Annales Zoologici Fennici 39: 109-123.

Macharia JM, Thenya T, Ndiritu GG. 2010. Management of highland wetlands in central Kenya: the importance of community education, awareness and eco-tourism in biodiversity conservation. Biodiversity (Nepean) 11: 85-90.

Masser MP, Jensen JW. 1991. USDA Grant 89-38500-4516. Calculating area and volume of ponds and tanks. Washington, DC: Southern Regional Aquaculture Center.

MEMR (Ministry of Environment and Mineral Resources). 2012. Kenya wetlands Atlas. www.environment.go.ke. [Accessed 21 February 2013].

Merritt RW, Cummins KW, Berg MB. 2008. An Introduction to the Aquatic Insects of North America. 4th Ed. Dubuque, United States: Kendall/Hunt Publishing Company.

Muli JR. 2005. Spatial variation of benthic macroinvertebrates and the environmental factors influencing their distribution in Lake Victoria, Kenya. Aquatic Ecosystem Health \& Management 8(2): 147-157.

Murkin HR, Wrubleski D A, Reid FA. 1994. Sampling invertebrates in aquatic and terrestrial habitats. (p 349-369). In: Research and Management Techniques for Wildlife and Habitats, 5th ed. Bookhout TA (Ed.). Bethesda, Maryland, USA: Wildlife Society.

NEMA (National Environmental Management Authority). 2011. Kenya state of the environment and outlook 2010: supporting the delivery of Vision 2030. Nairobi, Kenya: National Environmental Management Authority.

NEMA (National Environmental Management Authority). 2012. Wetlands assessment and monitoring strategy for Kenya. Nairobi, Kenya: National Environmental Management Authority.
Ng'weno F. 1992. Seasonal wetlands in Nairobi. (p 55-64). In: Crafter SA, Njuguna SG, Howard GW (Eds). Wetlands of Kenya. Proceedings of the Kenya Wetland Working Group Seminar on wetlands of Kenya. Nairobi, Kenya: National Museums of Kenya.

Nyingi WD. 2013. Guide to common freshwater fishes of Kenya. Nairobi, Kenya: Moran Publishers Ltd.

Oertli B, Biggs J, Céréghino R Grillas $P$, Joly $P$, Lachavanne J-B. 2005. Conservation and monitoring of pond biodiversity: introduction. Aquatic Conservation 15: 535-540.

RAMSAR (Ramsar Convention Secretariat). 2010. Inventory, assessment, and monitoring: an Integrated Framework for wetland inventory, assessment, and monitoring. Ramsar handbooks for the wise use of wetlands. 4th Ed. Vol. 13. Gland, Switzerland: Ramsar Convention Secretariat.

Ruhí A, Herrmann J, Gascón S, Sala J, Geijer J, Boix D. 2012. Change in biological traits and community structure of macroinvertebrates through primary succession in a man-made Swedish wetland. Freshwater Science 31: 22-37.

Sekiranda SBK, Okot-Okumu J, Bugenyi FWB, Ndawula LM, Gandhi P. 2004. Variation in composition of macro-benthic invertebrates as an indication of water quality status in three bays in Lake Victoria. Uganda Journal of Agricultural Sciences 9(1): 396-411.

Semlitsch RD. 2000. Size does matter. The value of small isolated wetlands. National Wetlands Newsletter January-February 5-7. Washington, DC, United States: Environmental Law Institute.

Semlitsch RD, Bodie JR 1998. Are small, isolated wetlands expendable? Conservation Biology 12: 1129-1133.

Sutherland WJ. 2013. Ecological census techniques. Cambridge, United Kingdom: Cambridge University Press.

Talling, J.F. 2011. Some distinctive subject contributions from tropical Africa to fundamental science of inland waters. Inland Waters 1(1): 61-73.

WHO (World Health Organization). 2005. Ecosystem and human well-being: a report of the Millennium Ecosystem Assessment. Geneva, Switzerland: WHO Press.

Zimmerman DA, Turner DA, Pearson DJ. 2005. Birds of Kenya and northern Tanzania. Princeton, New Jersey, United States: Princeton University Press. 


\section{Appendix: Questionnaires used during this study}

\section{Karura Forest Questionnaire}

Dear Visitor,

Welcome to Karura forest reserve

This survey aims to obtain your views about your visit Karura Forest and specifically whether you visit the Lily Pond Wetland. We hope you can spare the time to fill out this questionnaire as your feedback will help manage this Karura Forest better.

This survey will only take a few minutes to complete. Thank you for sharing your thoughts and ideas.

1. What is the highest level of your education?
Primary
Secondary
College
University

2. How many times in the past have you visited the Lily Pond wetland?

First visit

Frequently(2-5 times every month)

Few times every year

3. Which of the categories below best describes you or your group?

Visiting alone

Family

With friends and/or relatives

Community/education group(school)

Other(please specify)

4. Main purpose of visit

Educational

Recreational

Other(specify)

5. How long did you stay/or plan to stay in the reserve?

Short stop(under 2 hours)

Half day(2-4 hours)

All day(4-8 hours)

6. Describe how each of the following areas in the forest attract and satisfy your stay in Karura Forest

\begin{tabular}{|l|c|c|c|c|c|}
\hline & \multicolumn{4}{|c|}{ Importance level rating } \\
\hline Please rate how important each benefit is for you as a visitor & Very low & Low & Neutral & High & Very high \\
\hline Walking trails & 1 & 2 & 3 & 4 & 5 \\
\hline Forest and trees & 1 & 2 & 3 & 4 & 5 \\
\hline Swamps, rivers and ponds & 1 & 2 & 3 & 4 & 5 \\
\hline Playing fields & & & & & \\
\hline Restaurant & & & & \\
\hline
\end{tabular}

Specifically describe personal benefits you obtain at the Lily pond wetland.

\begin{tabular}{|l|c|c|c|c|c|}
\hline & \multicolumn{5}{|c|}{ Importance level rating } \\
\hline Please rate how important each benefit is for you as a visitor & Very low & Low & Neutral & High & Very high \\
\hline Learning about nature and natural environment & 1 & 2 & 3 & 4 & 5 \\
\hline Enjoy the scenery and aesthetic parts & 1 & 2 & 3 & 4 & 5 \\
\hline Engaging in recreational activities & 1 & 2 & 3 & 4 & 5 \\
\hline
\end{tabular}

Thank you very much for taking the time to complete this survey. Have a splendid day.

Date of visit: 1 